\title{
The use of salinity contrast for density difference compensation to improve the thermal recovery efficiency in high-temperature aquifer thermal energy storage systems
}

\author{
Jan H. van Lopik ${ }^{1,2}$ • Niels Hartog ${ }^{1,2}$ - Willem Jan Zaadnoordijk ${ }^{2,3}$
}

Received: 5 September 2015 / Accepted: 6 January 2016 / Published online: 18 February 2016

(C) Springer-Verlag Berlin Heidelberg 2016

\begin{abstract}
The efficiency of heat recovery in high-temperature $\left(>60{ }^{\circ} \mathrm{C}\right)$ aquifer thermal energy storage (HT-ATES) systems is limited due to the buoyancy of the injected hot water. This study investigates the potential to improve the efficiency through compensation of the density difference by increased salinity of the injected hot water for a single injection-recovery well scheme. The proposed method was tested through numerical modeling with SEAWATv4, considering seasonal HT-ATES with four consecutive injection-storage-recovery cycles. Recovery efficiencies for the consecutive cycles were investigated for six cases with three simulated scenarios: (a) regular HT-ATES, (b) HT-ATES with density difference compensation using saline water, and (c) theoretical regular HT-ATES without free thermal convection. For the reference case, in which $80^{\circ} \mathrm{C}$ water was injected into a high-permeability aquifer, regular HT-ATES had an efficiency of 0.40 after four consecutive recovery cycles. The density difference compensation method resulted in an efficiency of 0.69 , approximating the theoretical case (0.76). Sensitivity analysis showed that the net efficiency increase by using the density difference compensation method instead of regular HT-ATES is greater for higher aquifer hydraulic conductivity, larger temperature difference between injection water and
\end{abstract}

Jan H. van Lopik

j.h.vanlopik@uu.nl

1 Department of Earth Sciences. Environmental Hydrogeology group, Utrecht University, Budapestlaan 4, 3584

CD Utrecht, The Netherlands

2 KWR Watercycle Research Institute, Groningenhaven 7, 3433 PE Nieuwegein, The Netherlands

3 Water Resources Section, Faculty of Civil Engineering and Geosciences, Delft University of Technology, Stevinweg 1, 2628 CN Delft, The Netherlands ambient groundwater, smaller injection volume, and larger aquifer thickness. This means that density difference compensation allows the application of HT-ATES in thicker, more permeable aquifers and with larger temperatures than would be considered for regular HT-ATES systems.

Keywords Aquifer thermal energy storage (ATES) · Density difference compensation · Groundwater density · Recovery efficiency $\cdot$ Numerical modeling

\section{Introduction}

The rising demand for sustainable energy sources and $\mathrm{CO}_{2}$ emission reduction has led to intensified use of seasonal aquifer thermal energy storage (ATES) systems (Sanner et al. 2003). Thus far, ATES is mainly used for seasonal heating and cooling of buildings, where hot water is injected in the subsurface during summers and extracted during winters, and vice versa. Currently, the majority of ATES systems have limited temperature differences $\left(\Delta T<15^{\circ} \mathrm{C}\right)$ between the ambient groundwater on the one hand, and the injected warm and cold water on the other hand. The number of high temperature aquifer thermal energy storage (HT-ATES) systems is still limited, although the storage of water with higher temperatures (e.g. $>70^{\circ} \mathrm{C}$ ) increases both the energy storage capacity and overall energy efficiency (e.g. Kabus and Seibt 2000; Sanner et al. 2005; Réveillère et al. 2013). A huge amount of waste heat is produced worldwide in a wide range of industrial processes such as from incinerator and electricity plants (Meyer and Todd 1973). Therefore, HT-ATES systems can play a critical role in buffering the temporal mismatch between (continuous) heat supply and (seasonal) demand.

To date, most of the technical challenges induced by the high temperatures that hampered the early growth in the number of HT-ATES systems have now been resolved, such as 
appropriate water treatment and material selection to prevent the occurrence of mineral scaling and corrosion (Sanner et al. 2003). However, the economic feasibility of HT-ATES systems is largely determined by the thermal recovery efficiency, and relative low thermal recoveries up to values of only 0.42 were obtained during HT-ATES field experiments conducted in both confined and unconfined sandy aquifers (e.g. Mathey 1977; Palmer et al. 1992; Molz et al. 1979; 1983a, b).

Besides heat loss due to thermal conduction to colder surrounding formations (e.g. Doughty et al. 1982), free thermal convection during HT-ATES negatively impacts thermal energy recovery (e.g. Buscheck et al. 1983; Molz et al. 1983a). The temperature difference between hot injection water and cold ambient groundwater results in a net buoyancy difference. Therefore, buoyancy forces cause upward flow of hot injection water which results in tilting of the initially vertical hot water front (Fig. 1a,b). Also, the viscosity of water at elevated temperatures is lowered, resulting in enhanced free thermal convection (Hellström et al. 1979). Field experiments (e.g. Molz et al. 1983a) show that HT-ATES in high-permeability aquifers at high temperature contrasts between injected water $\left(81^{\circ} \mathrm{C}\right)$ and ambient groundwater $\left(20^{\circ} \mathrm{C}\right)$ result in significant free thermal convection and hence a low thermal recovery $(0.45)$.

The use of lower storage temperatures and the selection of low-permeability target aquifers are currently seen as the main design options for HT-ATES systems to reduce heat losses due to density-driven flow (e.g. Doughty et al. 1982; Schout et al. 2014). However, besides limiting the range of suitable aquifers and the use of lower, energetically less attractive, storage temperatures, the selection of low-permeability aquifers negatively impacts the hydraulic capacity of a HT-ATES system, and therefore the heat storage capacity. Moreover, the selection of lowpermeability aquifers increases the risk of well clogging by particles (e.g. Olsthoorn 1982). Therefore, the work reported here studies the possibility of minimizing free thermal convection in HT-ATES systems by using saline water for heat storage to compensate for the density difference with the ambient, cooler and less saline groundwater. Potentially, this would significantly increase recovery efficiencies and enable the use of higher permeability aquifers and higher injection temperatures for HTATES systems. This study explored the potential of this approach with numerical density-dependent flow simulations of (a) regular HT-ATES systems, (b) HT-ATES systems with density difference compensation using saline water, and (c) theoretical regular HT-ATES cases that consider no free thermal convection by neglecting density differences due to the temperature contrast between hot injection water and cold ambient groundwater. The latter scenario provided an upper bound for the improvement obtainable with density difference compensation. Firstly, a sensitivity analysis was performed by simulating multiple seasonal HT-ATES recovery cycles at various aquifer and environmental conditions. Secondly, the density difference compensation method was simulated for an actual HT-ATES system, a pilot in a highly permeable aquifer (Molz et al. 1983a; Buscheck et al. 1983).

\section{Methods}

\section{SEAWAT}

To simulate water, heat and solute transport during the HTATES recovery cycles, SEAWATv4 was used (Langevin et al. 2008; Guo and Langevin 2002). This code is a coupled version of the groundwater flow simulation program MODFLOW2000 (Harbaugh et al. 2000) and the multi-species mass transport simulation program MT3DMS (Zheng and Wang 1999), which enables simulation of variable-density groundwater flow. To allow for heat transport, the differential equations for solute transport in SEAWATv4 were translated in terms of heat transport following the approach described by Langevin et al. (2008).

Equations of state for density and viscosity were used to describe both fluid density and viscosity as a function of temperature and salt concentration. Fluid viscosity as a function of temperature and salt concentration is described by the following equation (Voss 1984):

$\mu\left(C_{\mathrm{S}}, T\right)=2.394 \cdot 10^{-5} \cdot 10^{\left(\frac{248.37}{T+133.15}\right)}+1.923 \cdot 10^{-6}\left(C_{\mathrm{S}}\right)$

where $\mu$ is the dynamic fluid viscosity ( $\mathrm{kg} / \mathrm{m}$ day), $T$ is the temperature of the water $\left({ }^{\circ} \mathrm{C}\right)$ and $C_{\mathrm{s}}$ is the solute concentration of the water $\left(\mathrm{kg} / \mathrm{m}^{3}\right)$.

A non-linear density equation of state derived by Sharqawy et al. (2010) was used in the SEAWAT code as described by Van Lopik et al. (2015) to accurately simulate the temperature-density relation over large temperature ranges (see Eq. 2). This density relationship based on experimentally derived datasets for both salt concentration and temperature at $1 \mathrm{~atm}$ pressure from Isdale and Morris (1972) and Millero and Poisson (1981) is shown in Fig. 2.

$$
\begin{gathered}
\rho(T, S)=\left(999.9+2.034 \cdot 10^{-2} T-6.162 \cdot 10^{-3} T^{2}+2.261 \cdot 10^{-5} T^{3}-4.657 \cdot 10^{-8} T^{4}\right)+ \\
\left(802.0 \frac{S}{1000}-2.001 \frac{S}{1000} T+1.677 \cdot 10^{-2} \frac{S}{1000} T^{2}-3.060 \cdot 10^{-5} \frac{S}{1000} T^{3}-1.613 \cdot 10^{-5}\left(\frac{S}{1000}\right)^{2} T^{2}\right)
\end{gathered}
$$

where $\rho$ is the fluid density $\left(\mathrm{kg} / \mathrm{m}^{3}\right)$ and $S$ is the salinity of the water $(\mathrm{g} / \mathrm{kg})$. 
Fig. 1 Schematic overview of a full HT-ATES recovery cycle in a confined aquifer for a injection, $\mathbf{b}$ storage and $\mathbf{c}$ extraction periods. Heat loss occurs by thermal conduction and free thermal convection (a)

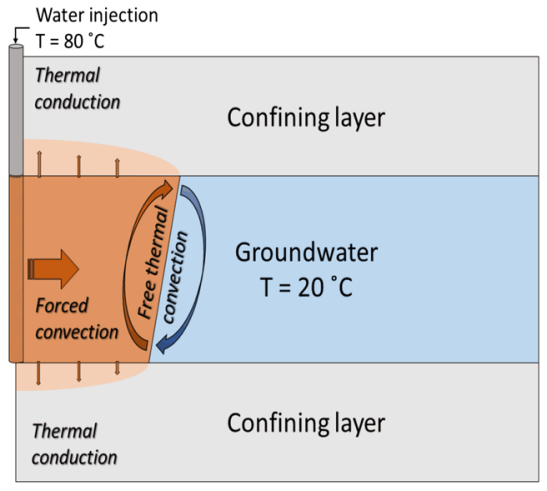

(b)

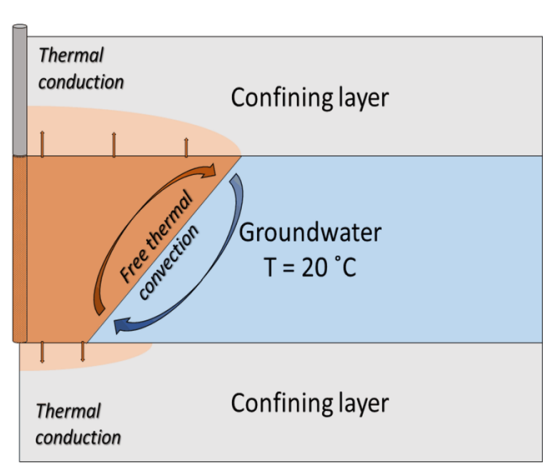

(c)

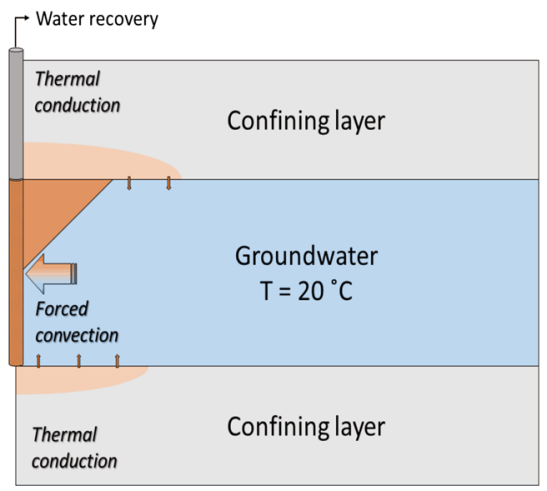

\section{Model set-up}

The modeling in the present study is done in two parts. Firstly, a sensitivity analysis is performed by simulation of seasonal HTATES with four consecutive recovery cycles (see section 'Generalized HT-ATES cases used for the sensitivity analysis').

Fig. 2 Water density as a

function of temperature and salinity (Sharqawy et al. 2010, Eq. 2). Solid lines represent equal water densities (isopycnals). The black stars show the required salinity for HT-ATES water injection at temperatures of 60 and $80^{\circ} \mathrm{C}$ into brackish groundwater with a temperature of $20^{\circ} \mathrm{C}$ (brackish $=10 \mathrm{~g} / \mathrm{kg}$ ). The red crosses are for water injection at temperatures of 58.5 and $81{ }^{\circ} \mathrm{C}$ into fresh groundwater with a temperature of $20^{\circ} \mathrm{C}$
Secondly, the density difference compensation method was tested for an actual HT-ATES field pilot of two recovery cycles in a high-permeability aquifer conducted by Molz et al. 1983a (see section 'Pilot study at the Auburn University'). For both the sensitivity analysis on seasonal HT-ATES and the numerical simulation of the field pilot, a confined sandy aquifer was con-

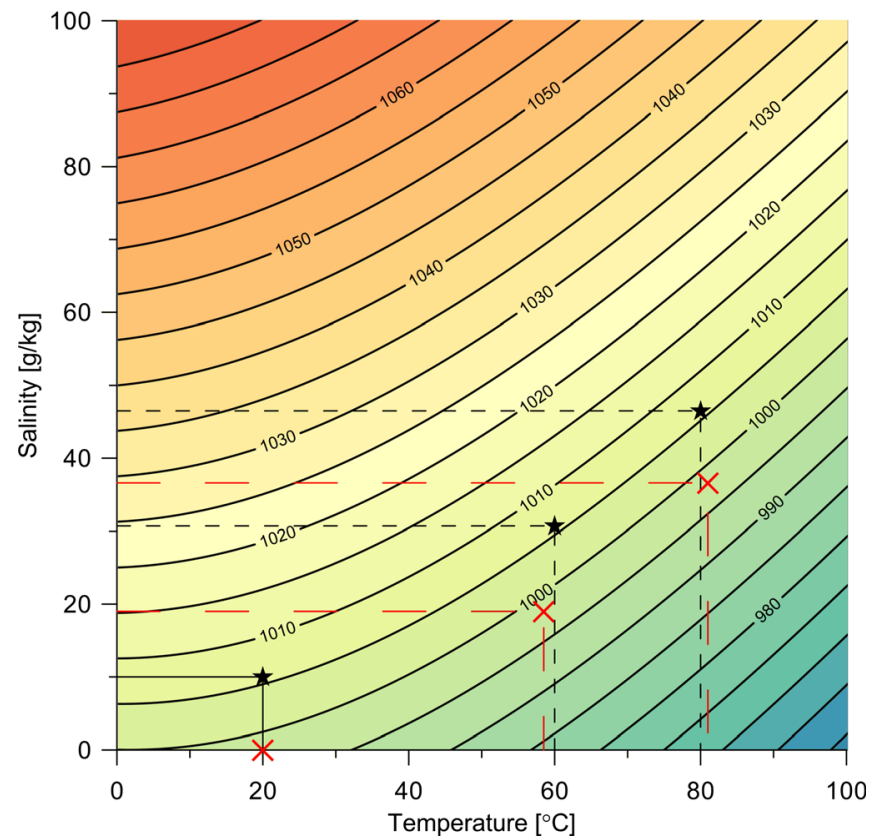


sidered to simulate HT-ATES recovery cycles at the various temperature and salt-concentration contrasts between injected water and ambient groundwater. Groundwater flow and associated heat and salt transport were simulated axi-symmetrically, following the approach introduced by Langevin (2008). This approach has been validated for transport of solute (Wallis et al. 2013) and heat (Vandenbohede et al. 2014). Although the displacement of heat and solutes by regional groundwater flow cannot be considered with the axi-symmetric approach, the regional groundwater flow is generally low in deep brackish aquifers targeted for HT-ATES systems (e.g. Sauty et al. 1982). Hence, neglecting heat and solute loss by regional groundwater flow during HT-ATES is considered a reasonable assumption.

The axi-symmetric model domain has a radius of $500 \mathrm{~m}$ with an aquifer thickness of $21 \mathrm{~m}$. The overlying and underlying aquitards are 10 and $9 \mathrm{~m}$ thick. The grid resolution is $\Delta r=0.5 \mathrm{~m}$ by $\Delta z=0.5 \mathrm{~m}$. Constant head, temperature and concentration boundaries were used for the outer, upper and lower boundaries of the model domain, following Buscheck et al. (1983). The inner boundary is impermeable inside the aquitards and simulates the well inside the aquifer. The well used for both injection and extraction has a radius of $0.1 \mathrm{~m}$. The groundwater flow is solved using the Preconditioned Conjugate Gradient 2 (PCG2) package. The modified method of characteristics (MMOC) is applied as an advection package with a Courant number 0.2. In order to simulate heat conduction accurately, the convergence criterion of relative temperature is set to $10^{-10}{ }^{\circ} \mathrm{C}$ (Vandenbohede et al. 2014).

\section{Generalized HT-ATES cases used for the sensitivity analysis}

The aquifer characteristics used for the simulation of seasonal HT-ATES are based on the aquifer used for the Auburn University (USA) field experiment conducted by Molz et al. (1983a). A homogeneous anisotropic aquifer has been used for the sensitivity analysis instead of the heterogeneous layering described by Buscheck et al. (1983). The aquifer characteristics for this base of the sensitivity analysis (case 1) are listed in Table 1 . The ambient groundwater in the sensitivity analysis has a brackish salinity of $10,000 \mathrm{ppm}\left(C_{\mathrm{s}}=10 \mathrm{~kg} / \mathrm{m}^{3}\right)$.

A seasonal HT-ATES system was assumed, with injection, storage, extraction and rest periods of 90 days each. Four consecutive cycles were simulated to investigate how the thermal recovery efficiency develops with time. An equal injection and extraction volume of $56,700 \mathrm{~m}^{3}$ and an injection temperature of $80{ }^{\circ} \mathrm{C}$ were assumed for each cycle in the reference scenario (case 1, Table 2). Three types of simulations (named $a, b$ and $c$ ) were conducted for all cases in the sensitivity analysis: regular HT-ATES (e.g. case 1.a for the reference scenario), HT-ATES with density difference compensation using saline water (e.g. case 1.b for the reference scenario), and a theoretical regular HT-ATES case that considers no free thermal convection and, hence, only heat loss by thermal conduction (e.g. case 1.c for the
Table 1 Aquifer and aquitard properties of the Auburn University field experiment (Molz et al. 1983a)

\begin{tabular}{ll}
\hline Properties & Parameter values \\
\hline Aquifer properties & $S_{\mathrm{s}}=6 \cdot 10^{-4} \mathrm{~m}^{-1}$ \\
Specific storage & $S_{\mathrm{s}}=6 \cdot 10^{-4} \mathrm{~m}^{-1}$ \\
Porosity & $\theta=0.25$ \\
Bulk density & $\rho_{\mathrm{b}}=1,950 \mathrm{~kg} / \mathrm{m}^{3}$ \\
Heat capacity & $c_{\mathrm{ps}}=696.15 \mathrm{~J} / \mathrm{kg}^{\circ} \mathrm{C}$ \\
Thermal conductivity of aquifer & $\lambda_{\mathrm{s}}=2.29 \mathrm{~W} / \mathrm{m}^{\circ} \mathrm{C}$ \\
Thermal distribution coefficient & $K_{\mathrm{dT}}=1.66 \cdot 10^{-4} \mathrm{~m}^{3} / \mathrm{kg}$ \\
Thermal retardation factor & $R_{\mathrm{T}}=2.29$ \\
Bulk thermal diffusivity & $D_{\mathrm{T}}=0.189 \mathrm{~m}{ }^{2} /$ day \\
Overall horizontal hydraulic conductivity & $k_{\mathrm{h}}=53.4 \mathrm{~m} / \mathrm{day}$ \\
Overall vertical hydraulic conductivity & $k_{\mathrm{v}}=7.7 \mathrm{~m} / \mathrm{day}$ \\
Aquifer thickness & $H_{\mathrm{a}}=21 \mathrm{~m}$
\end{tabular}

Aquitard properties

Specific storage

Porosity

Bulk density

Heat capacity

Thermal conductivity

Thermal distribution coefficient ${ }^{\mathrm{a}}$

Bulk thermal diffusivity ${ }^{\mathrm{a}}$

Horizontal hydraulic conductivity

Vertical hydraulic conductivity

$$
\begin{aligned}
& S_{\mathrm{s}}=9 \cdot 10^{-2} \mathrm{~m}^{-1} \\
& \theta=0.35 \\
& \rho_{\mathrm{b}}=1,690 \mathrm{~kg} / \mathrm{m}^{3} \\
& c_{\mathrm{ps}}=696.15 \mathrm{~J} / \mathrm{kg}{ }^{\circ} \mathrm{C} \\
& \lambda_{\mathrm{s}}=2.56 \mathrm{~W} / \mathrm{m}^{\circ} \mathrm{C} \\
& K_{\mathrm{dT}}=1.66 \cdot 10^{-4} \mathrm{~m}^{3} / \mathrm{kg} \\
& D_{\mathrm{T}}=0.151 \mathrm{~m}^{2} / \text { day } \\
& k_{\mathrm{h}}=53.4 \mathrm{~m} / \text { day } \\
& k_{\mathrm{v}}=7.7 \mathrm{~m} / \text { day }
\end{aligned}
$$

Groundwater properties

Heat capacity of the fluid

Thermal conductivity of the fluid

$c_{\mathrm{pf}}=4,186 \mathrm{~J} / \mathrm{kg}{ }^{\circ} \mathrm{C}$

$\lambda_{1}=0.58 \mathrm{~W} / \mathrm{m}^{\circ} \mathrm{C}$

Solute transport properties

Longitudinal dispersion

Transversal dispersion

Molecular diffusion

$\alpha_{1}=0.5 \mathrm{~m}$

$\alpha_{\mathrm{t}}=0.05 \mathrm{~m}$

$D_{\mathrm{m}}=8.64 \cdot 10^{-5} \mathrm{~m}^{2} /$ day

${ }^{\mathrm{a}}$ The thermal distribution coefficient $\left(K_{\mathrm{dT}}\right)$, thermal retardation factor $\left(R_{\mathrm{T}}\right)$, bulk thermal diffusivity $\left(D_{\mathrm{T}}\right)$ are calculated for SEAWATv4 heat transport simulation (see Langevin et al. 2008)

reference scenario). In the latter simulation (c), density-driven flow was not considered (no free thermal convection) as an upper bound for the improvement that can be obtained with density difference compensation. In the additional five cases with each three types of simulations, the sensitivity of the modeling results was investigated by varying HT-ATES conditions and aquifer characteristics (Table 2).

\section{Pilot study at the Auburn University}

The simulation (Buscheck et al. 1983) and experimental results (Molz et al. 1983a) of the HT-ATES field experiment conducted at the Auburn University were used to test the 
Table 2 Summary of the input parameters used for the sensitivity analysis

\begin{tabular}{llllll}
\hline & $k_{\mathrm{h}}[\mathrm{m} /$ day $]$ & $k_{\mathrm{v}}[\mathrm{m} /$ day $]$ & $T_{\text {in }}\left[{ }^{\circ} \mathrm{C}\right]$ & $H_{\mathrm{a}}[\mathrm{m}]$ & $V_{\text {in }}\left[\mathrm{m}^{3}\right]$ \\
\hline Case 1 & 53.4 & 7.7 & 80 & 21 & 56,700 \\
Case 2 & $15^{\mathrm{a}}$ & $1.5^{\mathrm{a}}$ & 80 & 21 & 56,700 \\
Case 3 & 53.4 & 7.7 & $60^{\mathrm{a}}$ & 21 & 56,700 \\
Case 4 & 53.4 & 7.7 & 80 & $10^{\mathrm{a}}$ & 56,700 \\
Case 5 & 53.4 & 7.7 & 80 & 21 & $28,350^{\mathrm{a}}$ \\
Case 6 & 53.4 & 7.7 & 80 & 21 & $113,400^{\mathrm{a}}$ \\
\hline
\end{tabular}

${ }^{\mathrm{a}}$ Indicates a variation on the reference scenario (case 1)

potential of density difference compensation with respect to the regular HT-ATES operated in this specific field experiment. The main aspects from Buscheck et al. (1983) and Molz et al. (1983a) are summarized here.

Two injection-storage-recovery cycles (injection temperatures of 58.5 and $81^{\circ} \mathrm{C}$ ) were conducted in a highly permeable sandy confined aquifer. The first cycle was of 3 months duration, while the second cycle had a duration of 7.3 months. The determined average production and injection volume rates and injection temperatures over time as presented by Buscheck et al. (1983) were used in the simulations of this study (Table 3). The characteristics of the aquifer and the confining layers used for the numerical modeling of this field experiment are listed in Table 1. A three-layered heterogeneous aquifer was considered with a 2.5 -fold higher hydraulic conductivity for the middle layer than for the upper and lower layers (Table 4) in order to predict the two recovery cycles numerically (Buscheck et al. 1983). The ambient groundwater temperature is $20{ }^{\circ} \mathrm{C}$ and contains only $280 \mathrm{ppm}$ or $0.28 \mathrm{~kg} / \mathrm{m}^{3}$ of total dissolved solids (Molz et al. 1983b). Due to low recovery temperatures of extracted water during the second recovery cycle, the well configuration was changed. The original fully penetrating well screen was replaced by a partially penetrating well screen after 2 weeks of extraction to increase thermal energy recovery, resulting in a recovery efficiency of 0.45 (Molz et al. 1983a). Molz et al. (1983a) estimated a thermal energy recovery efficiency of 0.40 without the partially penetrating well screen modification. Buscheck et al. (1983) simulated the second recovery cycle for a fully penetrating well screen. The same procedure is followed in the numerical simulation with SEAWATv4.

\section{Density difference compensation using saline water for heat storage}

The required salinity for the density difference compensation was calculated for the heat injection temperature based on the non-linear density equation (Eq. 2) as illustrated in Fig. 2. Salt mass transport was modeled conservatively and adsorption or precipitation reactions were not incorporated in the numerical simulations.

In the sensitivity analysis for various HT-ATES conditions (see section 'Generalized HT-ATES cases used for the sensitivity analysis'), a brackish salinity of $10,000 \mathrm{ppm}\left(10 \mathrm{~kg} / \mathrm{m}^{3}\right)$ was selected for the ambient groundwater, as environmental considerations typically preclude the use of HT-ATES in fresh
Table 3 Injection and extraction flow rates, as well as injection temperatures during the first and second cycle of the Auburn University field pilot (Buscheck et al. 1983). These values are used for the numerical simulation in this study

\begin{tabular}{|c|c|c|c|c|}
\hline Cycle & Phase & Length [days] & Volumetric flow rate $\left[\mathrm{m}^{3} /\right.$ day $]$ & Injection temperature $\left[{ }^{\circ} \mathrm{C}\right]$ \\
\hline \multicolumn{5}{|c|}{ Cycle-1 } \\
\hline & \multirow[t]{3}{*}{ Injection } & 20 & 760 & 60 \\
\hline & & 7 & 1,100 & 58 \\
\hline & & 4 & 600 & 52 \\
\hline & Storage & 32 & - & - \\
\hline & \multirow[t]{2}{*}{ Extraction } & 2 & $-1,684.8$ & - \\
\hline & & 21 & $-1,054.1$ & - \\
\hline & Rest & 26 & - & - \\
\hline \multicolumn{5}{|c|}{ Cycle-2 } \\
\hline & \multirow[t]{5}{*}{ Injection } & 8 & 954 & 85 \\
\hline & & 24 & - & - \\
\hline & & 7 & 600 & 82 \\
\hline & & 4 & - & - \\
\hline & & 85 & 545 & 80 \\
\hline & Storage & 34 & - & - \\
\hline & \multirow[t]{3}{*}{ Extraction } & 14 & $-1,088.6$ & - \\
\hline & & 2 & - & - \\
\hline & & 39 & $-1,088.6$ & - \\
\hline
\end{tabular}


Table 4 Hydraulic conductivity of the heterogeneous aquifer at Auburn University, according to Buscheck et al. (1983)

\begin{tabular}{ll}
\hline Hydraulic conductivity & Value \\
\hline Horizontal hydraulic conductivity & \\
$\quad$ Upper layer (10 m thick) & $k_{\mathrm{h}}=38.2 \mathrm{~m} /$ day \\
Middle layer (5 m thick) & $k_{\mathrm{h}}=96.4 \mathrm{~m} /$ day \\
Lower layer ( 6 m thick) & $k_{\mathrm{h}}=38.2 \mathrm{~m} /$ day \\
& \\
Vertical to horizontal hydraulic conductivity ratio & $1: 7$ \\
\hline
\end{tabular}

groundwater aquifers. The salt concentration required to establish the same water density as ambient groundwater ( $T=20{ }^{\circ} \mathrm{C}$ and $C_{\mathrm{s}}=10 \mathrm{~kg} / \mathrm{m}^{3}$ ) for hot injection water at temperatures of 60 and $80{ }^{\circ} \mathrm{C}$ is shown in Fig. 2. The required salt concentrations are 30.7 and $46.5 \mathrm{~kg} / \mathrm{m}^{3}$, respectively.

For the HT-ATES pilot study at Auburn University (see section 'Pilot study at the Auburn University'), the density difference between hot injection water and ambient groundwater was calculated for both cycles with injection temperatures of 58.5 and $81{ }^{\circ} \mathrm{C}$, respectively. Consequently, the required salt concentration to overcome buoyancy difference between injected water and ambient groundwater was $19 \mathrm{~kg} / \mathrm{m}^{3}$ for cycle-1, whereas for cycle-2, a salt concentration of $36.6 \mathrm{~kg} / \mathrm{m}^{3}$ was required (Fig. 2).

\section{Metrics to quantify salt and heat recovery}

Critical in the operation of HT-ATES systems is how much of the injected heat can be recovered following storage, expressed as thermal recovery efficiency. The thermal recovery efficiency $\left(\varepsilon_{\mathrm{H}}\right)$ is defined as the ratio between the total injected heat $\left(Q_{\text {in }}\right)$ and the total recovered heat after extraction $\left(Q_{\text {ex }}\right)$. The total injected and recovered heat is calculated from the temperatures of injected and extracted water:

$\varepsilon_{\mathrm{H}}=\frac{Q_{\mathrm{ex}}}{Q_{\text {in }}}=\frac{\sum\left[V_{\mathrm{ex}} \cdot \rho_{\mathrm{ex}}(T, S) \cdot c_{\mathrm{pf}} \cdot\left(T_{\mathrm{ex}}-T_{\mathrm{a}}\right)\right]}{\sum\left[V_{\text {in }} \cdot \rho_{\text {in }}(T, S) \cdot c_{\mathrm{pf}} \cdot\left(T_{\text {in }}-T_{\mathrm{a}}\right)\right]}$

where $V_{\text {ex/in }}$ are the volumes per time step of the extracted water and the injected water $\left(\mathrm{m}^{3}\right), T_{\mathrm{ex}}$ /in are the temperatures of the extracted water and the injected water $\left({ }^{\circ} \mathrm{C}\right), T_{\mathrm{a}}$ the ambient groundwater temperature $\left({ }^{\circ} \mathrm{C}\right), c_{\mathrm{pf}}$ the heat capacity of water, $\mathrm{J} /\left(\mathrm{kg}{ }^{\circ} \mathrm{C}\right)$, and $\rho_{\text {in/ex }}(\mathrm{T}, \mathrm{S})$ the densities of the extracted water and the injected water as a function of salt concentration and temperature (Eq. 2). In the sensitivity analysis (cases 1-6), summation is done over the output time steps for salinity and temperature ( $\Delta t=5$ days) to calculate $Q_{\text {in }}$ and $Q_{\text {ex }}$. For the Auburn University HT-ATES field experiment, smaller output time steps of 1 day are used.
For density difference compensation, the recovery of salt mass $\left(\varepsilon_{\mathrm{S}}\right)$ is an important variable in this study. The salt mass recovery efficiency is defined as the ratio between the total injected salt mass $\left(M_{\mathrm{S}}\right.$ in $)$ and the total recovered salt mass after extraction $\left(M_{\mathrm{S} \text { ex }}\right)$ :

$\varepsilon_{\mathrm{S}}=\frac{M_{\mathrm{Sex}}}{M_{\mathrm{Sin}}}=\frac{\sum\left[V_{\mathrm{ex}} \cdot\left(C_{\mathrm{S} \mathrm{ex}}-C_{\mathrm{S} \mathrm{a}}\right)\right]}{\sum\left[V_{\mathrm{in}} \cdot\left(C_{\mathrm{S} \text { in }}-C_{\mathrm{S} \mathrm{a}}\right)\right]}$

where $C_{\mathrm{S} \text { ex/in }}$ are the salt concentrations in each time step of the extracted water and the injected water $\left(\mathrm{kg} / \mathrm{m}^{3}\right)$ and $C_{\mathrm{S}}$ is the ambient groundwater concentration $\left(\mathrm{kg} / \mathrm{m}^{3}\right)$.

\section{Spreading of hot and saline water}

In the sensitivity analysis, theoretical optimal HT-ATES cases that considered only heat loss by thermal conduction (e.g. case 1.c) are run and compared to density difference compensation (e.g. case 1.b). Considering an optimal case with no heat loss, the shape of the stored hot water in the aquifer will be cylindrical. Therefore, the dimensions of the hot water volume can be described in terms of the maximum radial extent of the injected hot water $\left(r_{\text {th }}\right)$ and a given aquifer thickness $\left(H_{\mathrm{a}}\right)$.

Equilibration of heat between the solid and water phase occurs during heat transport in the aquifer. Therefore, the temperature front progresses at a lower rate into the aquifer than the effective flow velocity during hot water injection. The thermal radius of the hot injection water $\left(r_{\mathrm{th}}\right)$ is defined by the cylinder formed by retarded advective transport only:

$r_{\mathrm{th}}=\sqrt{\frac{V_{\mathrm{in}}}{\pi H_{\mathrm{a}} \theta R_{\mathrm{T}}}}$

where $\theta$ is the porosity, $H_{\mathrm{a}}$ is confined aquifer thickness (m) and $R_{\mathrm{T}}$ is the thermal retardation factor:

$R_{\mathrm{T}}=1+\frac{\rho_{\mathrm{b}}}{\theta} \frac{c_{\mathrm{ps}}}{\rho_{\mathrm{f}} c_{\mathrm{pf}}}$

where $\rho_{\mathrm{b}}$ is the bulk density $\left(\mathrm{kg} / \mathrm{m}^{3}\right)$ and $c_{\mathrm{ps}}$ the heat capacity of solid, $\mathrm{J} /\left(\mathrm{kg}{ }^{\circ} \mathrm{C}\right)$.

Similar to the thermal radius, a solute radius $\left(r_{\mathrm{s}}\right)$ can be defined considering conservative advective solute transport and neglecting molecular diffusion and dispersion:

$r_{\mathrm{s}}=\sqrt{\frac{V_{\mathrm{in}}}{\pi H_{\mathrm{a}} \theta}}$

\section{Results}

The results of this study are presented in two parts. First, the sensitivity analysis are presented in which various seasonal 
HT-ATES cases have been simulated for three scenarios: (a) a regular setup, (b) a setup with density difference compensation using saline water, and (c) a setup under the theoretical condition of no free thermal convection. Secondly, the results of the SEAWATv4 modelling of the two recovery cycles of the Auburn University field experiment performed with and without density difference compensation are presented.

\section{Sensitivity analysis}

Several cases were simulated to test the potential of density difference compensation for HT-ATES and its sensitivity for various conditions (see section 'Generalized HT-ATES cases used for the sensitivity analysis'). Four parameters were varied with respect to the reference scenario (case 1, Table 2): a lower aquifer hydraulic conductivity (case 2), a lower injection temperature (case 3), a smaller aquifer thickness (case 4), and a smaller and larger injection volume (cases 5 and 6).

\section{Reference scenario (case 1)}

In case 1, a seasonal HT-ATES system with injection temperatures of $80{ }^{\circ} \mathrm{C}$ is simulated both with and without density difference compensation. Without density difference compensation, the results showed strong free thermal convection during injection and storage for regular HT-ATES (case 1.a, Fig. 3). Consequently, unheated ambient groundwater is recovered at the lower part of the well screen and overall recovered water temperatures over time ranged between 49.6 and
$33.5{ }^{\circ} \mathrm{C}$ for cycle-1 (Fig. 4). The thermal recovery is low, ranging from 0.31 to 0.40 for the four recovery cycles (Fig. 5). Initially, the increase in thermal recovery efficiency is large $\left(\Delta \varepsilon_{\mathrm{H}}=0.051\right)$, but for the subsequent cycles the increase in recovery efficiency gradually decreases to an $\Delta \varepsilon_{\mathrm{H}}$ increase of only 0.015 from cycle- 3 to cycle- 4 . The buoyancy of the injected hot water decreases for each consecutive recovery cycle, which results in less pronounced thermal convection. Also the heat loss by thermal conduction decreases due to a lower temperature difference between injection water and ambient groundwater.

For the scenario with density difference compensation (case 1.b), the required salt concentration to reduce the density contrast between the hot injection water and the ambient groundwater is $46.5 \mathrm{~kg} / \mathrm{m}^{3}$ (Fig. 2). This means that a total salt mass of $2.07 \cdot 10^{6} \mathrm{~kg}$ was injected for each recovery cycle. The results show that free thermal convection during injection and storage was successfully countered (Fig. 6). A large increase in thermal recovery $\left(\Delta \varepsilon_{\mathrm{H}}=0.29\right)$ was obtained with respect to the regular HT-ATES (case 1.a) for each recovery cycle (Fig. 5). Moreover, the recovery temperatures over time were significantly better preserved with respect to the injection temperature (Fig. 4). The production temperature slightly decreases during the first 50 days of extraction when the stabilized hot water volume is recovered. This resulted in increased recovery temperatures up to $20{ }^{\circ} \mathrm{C}$ with respect to the regular HT-ATES (case 1.a). After 50 days, a rapid decline in production temperature is observed during recovery. In this period, hot water was recovered which was largely affected by
Fig. 3 Temperature distribution for the reference scenario of regular HT-ATES without density difference compensation (case 1.a): $\mathbf{a}$ at the end of the injection period, $\mathbf{b}$ at the end of the storage period and $\mathbf{c}$ at the end of the extraction period (a)

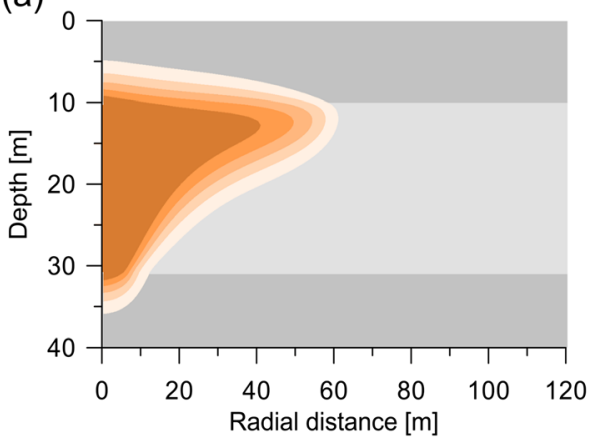

(c)

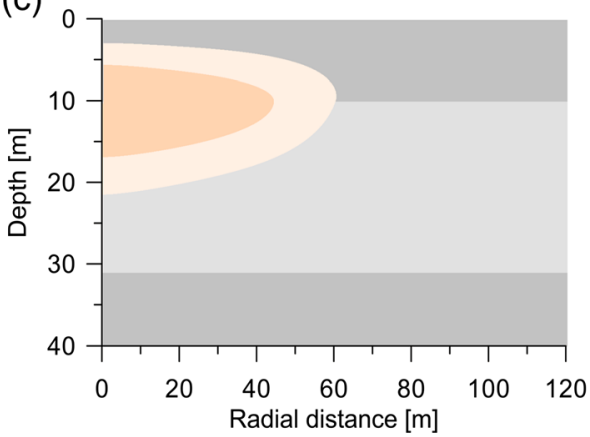

(b)

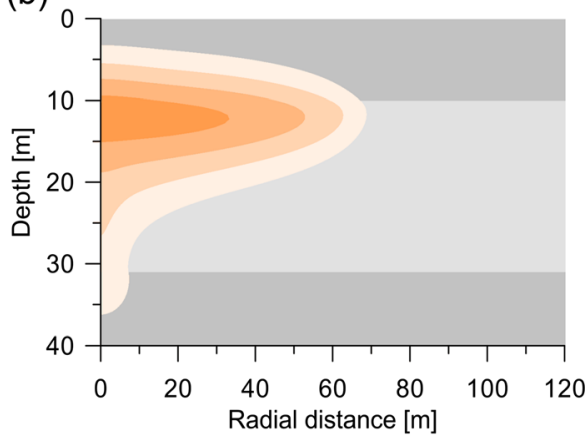

Temperature $\left[{ }^{\circ} \mathrm{C}\right]$

$\begin{array}{llllll}30 & 40 & 50 & 60 & 70 & 80\end{array}$ 


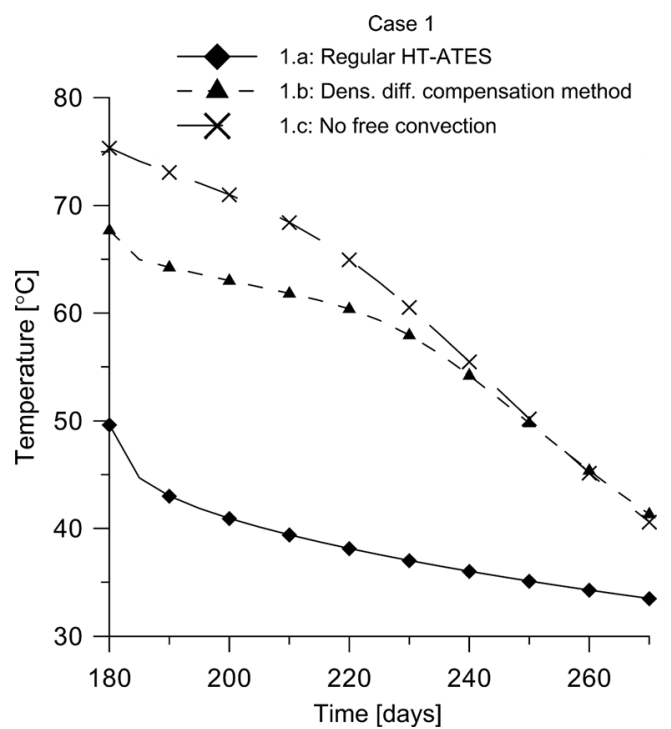

Fig. 4 Production temperatures over time for the first recovery period of case 1

the radial heat loss due to thermal conduction into the aquifer in the preliminary injection and storage stages, as was by the similar temperature decline when modeling the scenario without accounting for free thermal convection (case 1.c). Thus, besides reducing the heat loss due to free thermal convection, applying density difference compensation also reduced the heat loss by thermal conduction in comparison to the regular HT-ATES. This is due to the more compact, cylindrical hot water volume in the aquifer that is maintained when applying density difference compensation, which resulted in a smaller total contact area of both the colder surrounding aquifer and colder confining layers where heat is lost by thermal conduction (Fig. 6). The difference in thermal recovery between density difference compensation (case 1.b) and the theoretical case with no free thermal convection (case 1.c) is small $\left(\Delta \varepsilon_{\mathrm{H}}=0.07\right)$. This means that for case 1.b, the main heat loss occurs by thermal conduction. However, as reflected by the initially lower recovery temperatures compared to the scenario that ignores free thermal convection (case 1.c) for the first 50 days of extraction (Fig. 4), a small fraction of heat loss still occurs by a different mechanism. This is due to the fact that in the density difference compensated HT-ATES system free convection is determined by the density contrasts resulting from both the salt concentration and temperature differences in the aquifer. The thermal retardation (Eq. 6) affects heat transport, resulting in faster advective solute transport than heat transport during injection operations (e.g. Miotliński and Dillon 2015; Seibert et al. 2014). Therefore, plume separation of hot water (see Eq. 5) and saline water (see Eq. 7) occurs during HT-ATES with density difference compensation (case 1.b), which results in a cold saline water plume in front of the hot water volume. Oldenburg and Preuss (1999) showed that plume separation of saline and hot water highly affects convective flow patterns if the salt concentration and the temperature contrasts are large. For HT-ATES with density difference compensation (case 1.b), the injected salt concentration of $46.5 \mathrm{~kg} / \mathrm{m}^{3}$ creates a strong density contrast at ambient temperature with the ambient groundwater concentration $\left(C_{\mathrm{s}}=10 \mathrm{~kg} / \mathrm{m}^{3}\right)$ of approximately $28 \mathrm{~kg} / \mathrm{m}^{3}$ $\left(1,034 \mathrm{~kg} / \mathrm{m}^{3}\right.$ vs. $1,006 \mathrm{~kg} / \mathrm{m}^{3}$, Fig. 2). Hence, a downward buoyancy force is exerted on the cooled saltwater front resulting in downward transport (Fig. 6d-e). Due to downward density-driven flow of cold saltwater, the hot water volume at the bottom of the aquifer is displaced towards the well screen. Therefore, cold saline water was recovered at the lower part of the well screen (Fig 6b), resulting in lower recovery efficiencies than the theoretical optimal case when not considering free thermal convection (case 1.c). In the last stage of the extraction period (after 260 days), the recovered temperature is slightly higher for case 1.b than for case 1.c (Fig. 4). The displacement of the cold saline water towards the well screen
Fig. 5 Calculated a thermal and b salt mass recovery efficiency per cycle for the reference case 1 (a)

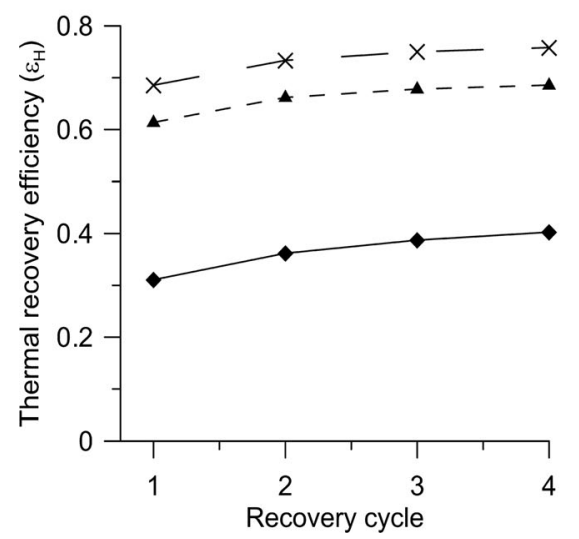

Case 1

1.a: Regular HT-ATES

- $\mathbf{A}$ - 1.b: Dens. diff. compensation method

(b)

$\rightarrow \quad$ 1.c: No free convection

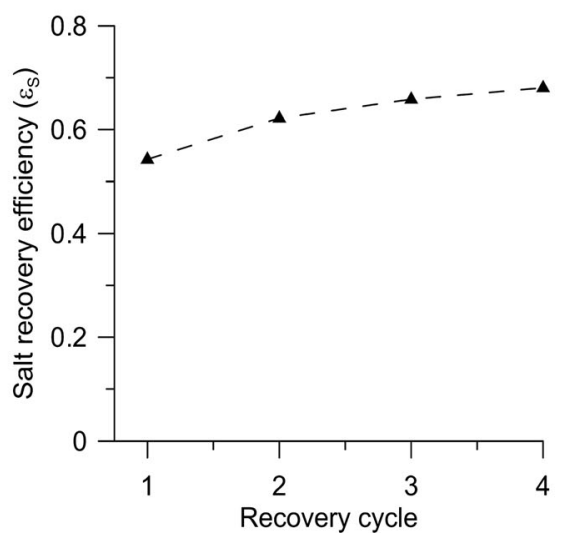


Fig. 6 Temperature distribution for the reference case with density difference compensation (case 1.b) at the end of a the injection period, $\mathbf{b}$ of the storage period, and $\mathbf{c}$ of the extraction period. Black contour lines indicate the temperature distribution for the regular reference case 1.a. The same is done for the salt concentration distribution at the end of $\mathbf{d}$ the injection period, $\mathbf{e}$ of the storage period, and $\mathbf{f}$ of the extraction period
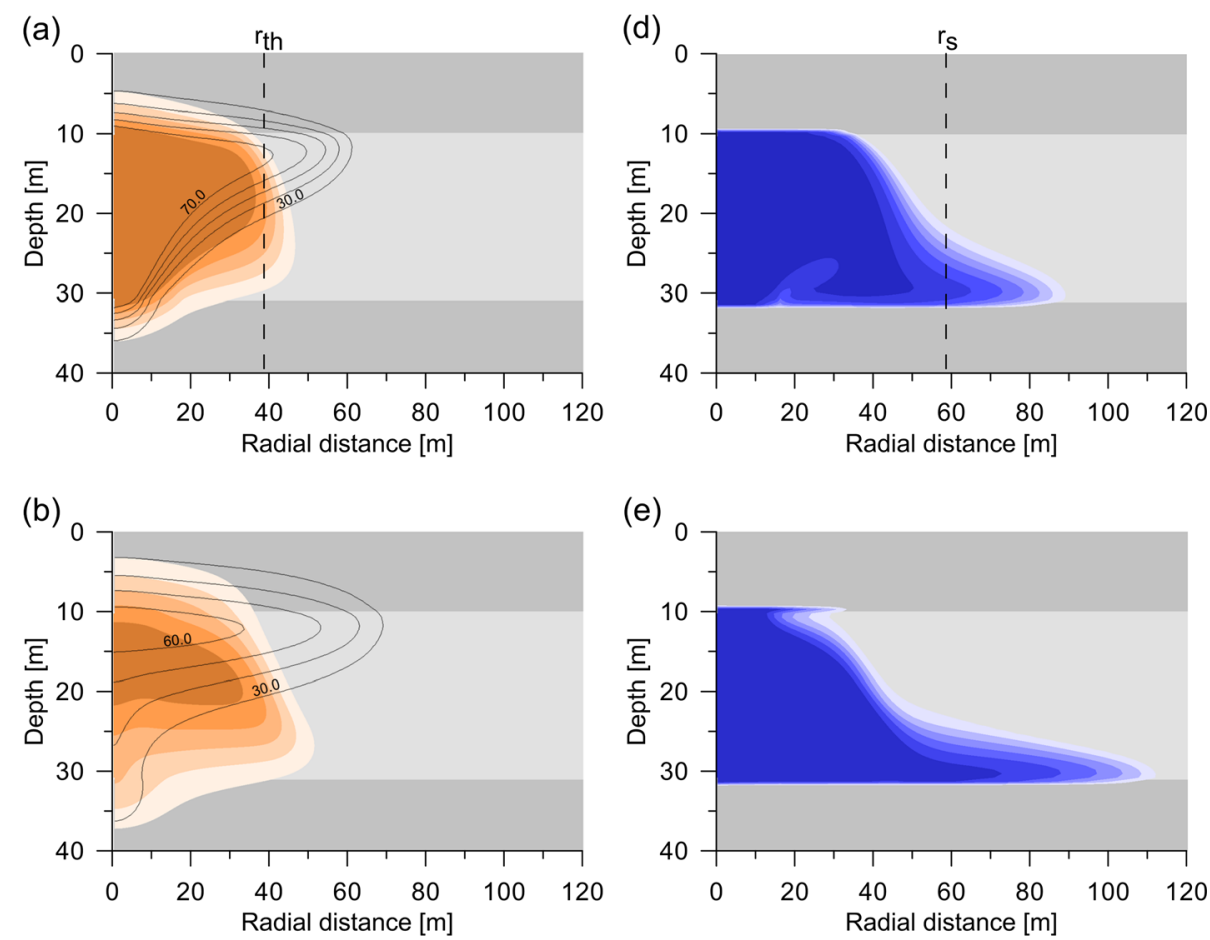

(c)

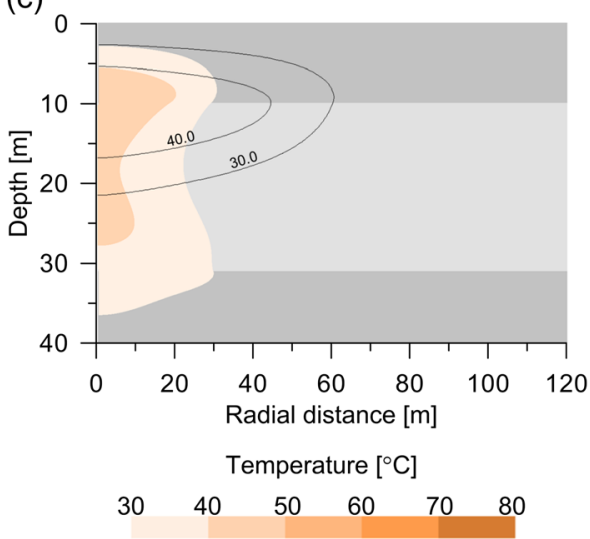

(f)

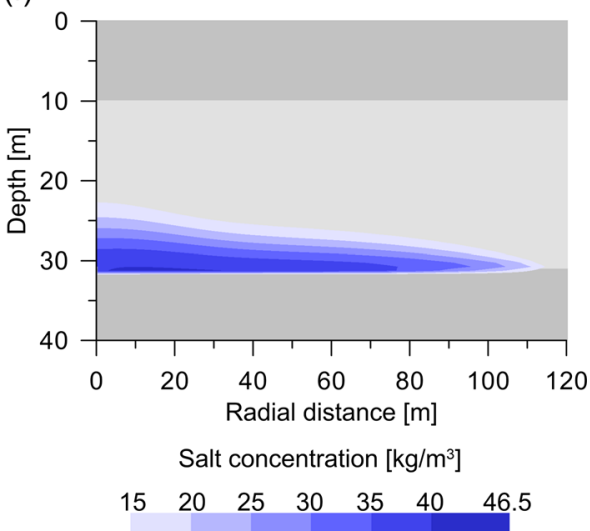

resulted in lateral transport of heated water away from the well screen in the upper part of the aquifer. Consequently, the heated water volume in the upper part of the well screen has moved further from the well than in the no free thermal convection scenario (case 1.c). In the final stage of extraction, this displaced heated water volume at the top of the aquifer is recovered, resulting in slightly higher recovery temperatures for the density difference compensation method.

In addition to the thermal recovery, the salt recovery was determined for the density difference compensation method, at 0.54 for the first cycle, after which it increases to a value of 0.68 in the fourth cycle (Fig. 5b). This resulted in an unrecovered salt mass of $1.21 \cdot 10^{6}$ and $8.42 \cdot 10^{5} \mathrm{~kg}$, respectively. Salt mass accumulates at the bottom of the aquifer after each extraction period. Only a small amount of saltwater is accumulated in the upper clay layer due to molecular diffusion during the injection and storage phase (Fig. 6f). For the first cycle, saltwater $\left(C_{\mathrm{s}}>12 \mathrm{~kg} / \mathrm{m}^{3}\right)$ is transported up to a radial distance of $124 \mathrm{~m}$ along the bottom of the aquifer, while this is $201 \mathrm{~m}$ for cycle-4.

\section{Hydraulic conductivity of the aquifer (case 2)}

Currently, low-permeability aquifers are selected for HT-ATES systems to reduce free thermal convection and to obtain sufficiently high thermal recovery efficiencies (e.g. Doughty et al. 1982; Schout et al. 2014). For case 2, an aquifer with a horizontal and vertical hydraulic conductivity of 15 and $1.5 \mathrm{~m} /$ day, respectively, was considered to account for such aquifers characteristics (instead of 53.4 and $7.7 \mathrm{~m} /$ day for case 1 ). The thermal recovery efficiencies for the regular HT-ATES (case 2.a) 
Fig. 7 a Calculated thermal and b salt recovery efficiency of cycle-4 for all cases

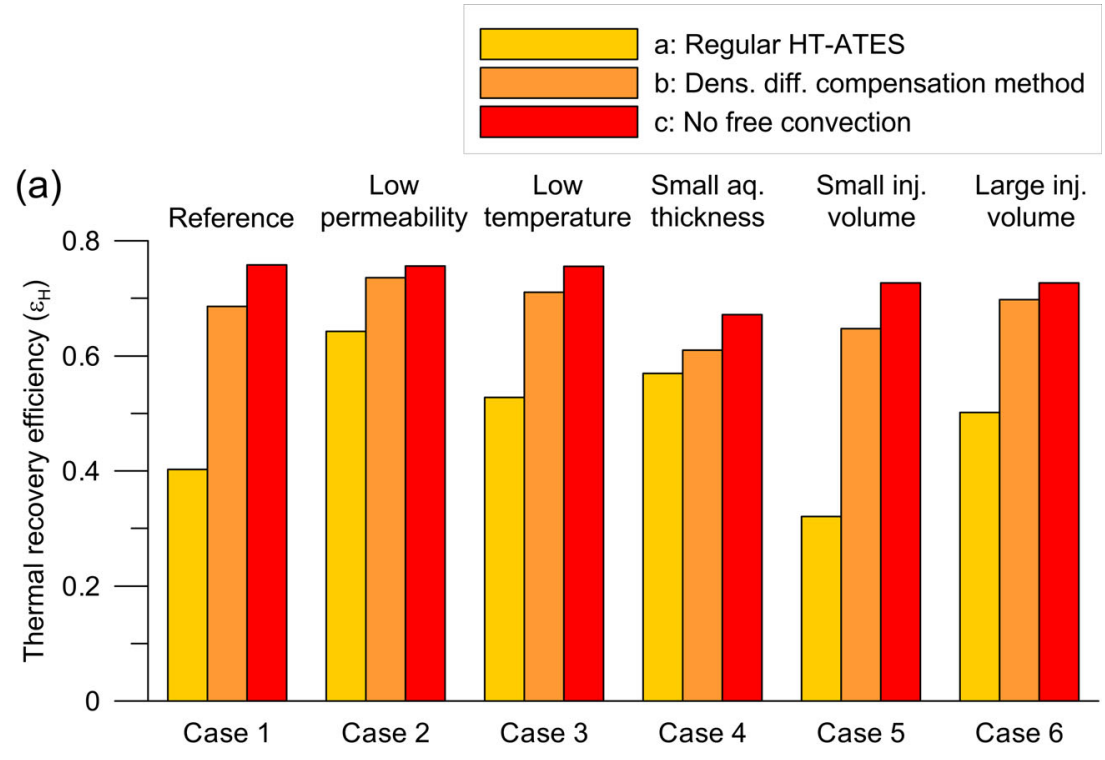

(b)

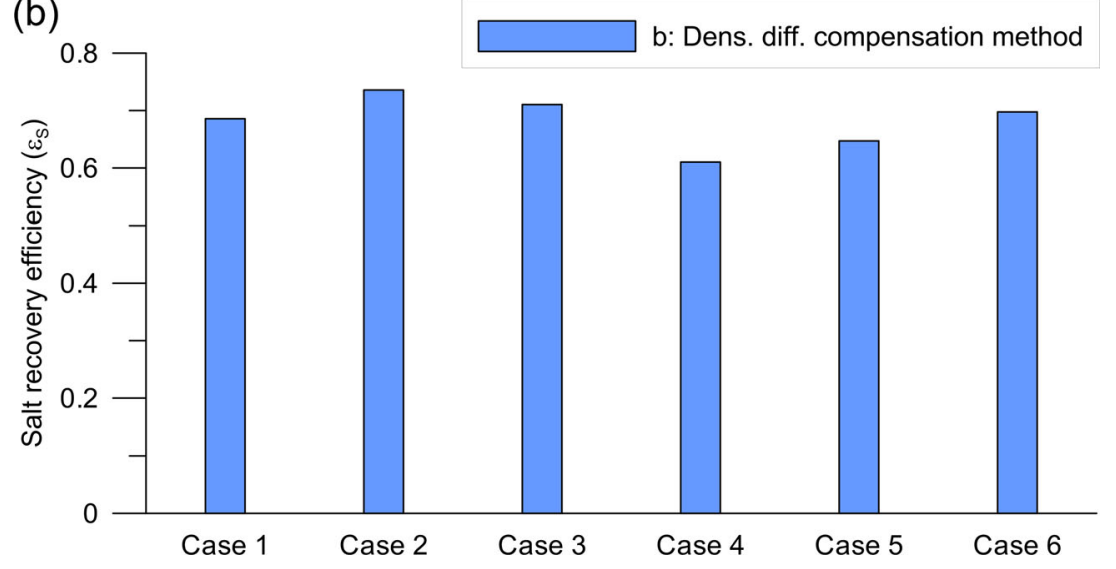

are elevated compared to the reference scenario (case 1.a) with values of 0.58 and 0.64 , for the first cycle and fourth cycle (Fig.7a), respectively. Although the effect was less, density difference compensation (case 2.b) still improved thermal recovery efficiency $\left(\Delta \varepsilon_{\mathrm{H}}\right)$ with 0.10 compared to regular HT-ATES (case 2.a). The recovered temperature declines substantially during extraction (Fig. 8). The downward salt-water transport between the solute and thermal front causes less displacement of the hot water towards the well screen due to decreased flow velocities. Therefore, the difference in thermal recovery $\left(\Delta \varepsilon_{\mathrm{H}}\right)$ between density difference compensation (case 2.b) and the optimal case with no free thermal convection (case 2.c) is only 0.02 for cycle-4 (Fig. 7a). Despite the significantly lower permeability, the efficiency of regular HT-ATES (case 2.a) was lower than for the density difference compensation in the high-permeability reference scenario (case 1.b).

Salt mass recovery efficiency is much higher for case 2.b, compared to the reference scenario, case 1.b (Fig. 7b). Downward density-driven flow of cold saltwater is restricted due to decreased hydraulic conductivity of the aquifer.
Consequently, the accumulation rate of salt mass at the bottom of the aquifer is low compared to case 1.b.

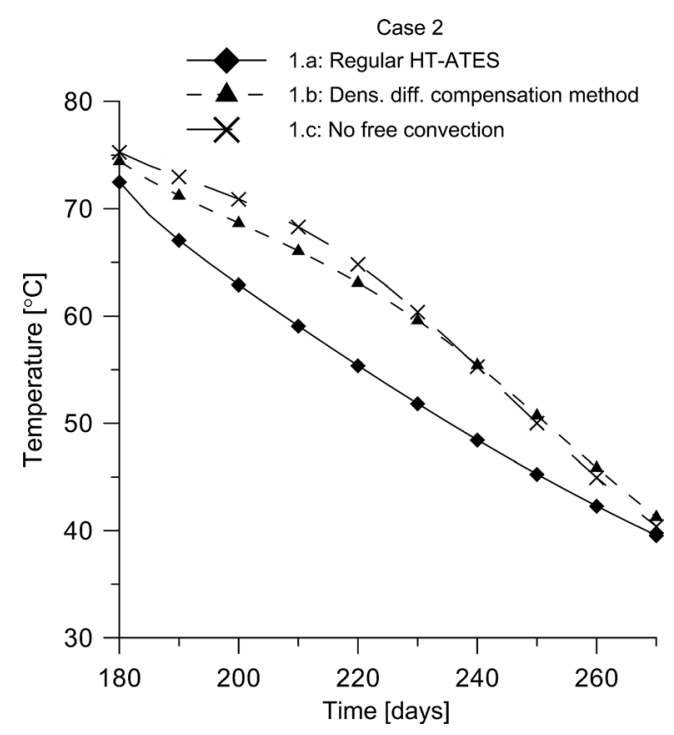

Fig. 8 Production temperatures over time of cycle-1 for case 2 


\section{Injection temperature (case 3)}

An injection temperature of $60^{\circ} \mathrm{C}$ was considered for case 3 , to test the effect of a lower temperature difference between hot injection water and ambient groundwater (Table 2). For regular HT-ATES, a higher thermal recovery efficiency was achieved with a lower injection temperature (case $3 . \mathrm{a} ; T_{\mathrm{i}}=60^{\circ} \mathrm{C}$ ) than for the reference scenario (case $1 . \mathrm{a} ; T_{\mathrm{i}}=80{ }^{\circ} \mathrm{C}$ ), due to less pronounced free thermal convection. For the theoretical cases where no free thermal convection was considered (case 1.c and case 3.c), the calculated thermal recovery efficiency was 0.76 for both. This independence of recovery efficiency on the injection temperature is due to the linear increase of both heat loss by thermal conduction and the total injected heat $\left(Q_{\text {in }}\right)$, with the resulting temperature contrast between hot injection water and the cold surrounding aquifer and aquitards.

For the density difference compensation scenario, a salt concentration of $30.7 \mathrm{~kg} / \mathrm{m}^{3}$ (Fig. 2) was required to overcome the buoyancy difference between hot injection water and ambient groundwater. The HT-ATES scenario with density difference compensation (case 3.b), resulted in a net recovery efficiency increase $\left(\Delta \varepsilon_{\mathrm{H}}\right)$ of 0.18 , with respect to regular HT-ATES (case 3.a). The recovery efficiency was close to the theoretical case with no free thermal convection (case 3.c) with a $\Delta \varepsilon_{\mathrm{H}}$ value of only 0.05 (Fig. 7a). This is caused by the less-pronounced downward saltwater transport for this scenario than in the reference scenario (case 1.b), due to the lower salt concentration contrast with the ambient groundwater. Consequently, the induced hot water displacement towards the well screen is less pronounced. In addition, the calculated salt recovery efficiency is higher for case 3.b than for the reference scenario (case 1.b), since the accumulation rate of salt at the bottom of the aquifer is lowered (Fig. 7b).

\section{Aquifer thickness and injection volume (cases 4-6)}

The sensitivity of the recovery efficiency for regular HTATES and with density difference compensation was tested for different injection volumes and aquifer thickness (Table 2).
This was done simulating a two times smaller aquifer thickness (case 4), as well as a two times smaller (case 5) and a two times larger injection volume (case 6) with respect to the reference (case 1).

For the regular HT-ATES cases 4.a and 6.a, the recovery efficiencies are higher and the maximum radii of heated volume are larger ( $r_{\text {th }}$, Table 5). The contrary is observed for the case with the smaller volume (case 5.a) which has the smallest $r_{\text {th }}$ value. For regular HT-ATES in a high-permeability aquifer, heat loss is mainly determined by free thermal convection. Consequently, thermal front tilting close to the well screen (e.g. case 5.a) resulted in recovery of large amounts of cool ambient groundwater at the lower part of the well screen during the extraction stage. Therefore, the largest increase in thermal recovery efficiency with density difference compensation is obtained for the scenarios with a small $r_{\text {th }}$ value, resulting in a $\Delta \varepsilon_{\mathrm{H}}$ value of 0.28 for case $1 . \mathrm{b}$ (compared to $1 . \mathrm{a}$ ) and 0.33 for case 5.b (compared to 5.a), respectively. A smaller aquifer thickness (case 4.b) results in an increase of only 0.04 , while for a higher injection volume (case 6.b) this is 0.20 (Fig. 7a).

The differences in thermal recovery between density difference compensation and the theoretical scenario without free thermal convection are small, with $\Delta \varepsilon_{\mathrm{H}}$ ranging from 0.06 to 0.08 for cases 1 and 4-6 (Fig. 7a). The hot water volume is not completely stabilized with density difference compensation, since hot water is displaced towards the well screen due to downward transport of the cold saltwater behind the solute front. However, this effect on thermal recovery is small and heat loss is mainly due to thermal conduction. Table 5 shows that the highest energy recovery is obtained for case 6.c, where the ratio between the outside area and thermal volume in the aquifer is lowest $\left(0.13 \mathrm{~m}^{-1}\right)$. A smaller injection volume (case 5.c) results in a larger ratio of $0.17 \mathrm{~m}^{-1}$ and a lower recovery efficiency. For small injection volumes, the overall surface area will be relatively large compared to the thermal volume. Therefore, the heat losses due to thermal conduction will be high.

The relative conductive heat loss to the surroundings with respect to the total amount of stored heat is highest for cases $4 . \mathrm{b}-\mathrm{c}$, with an area volume ratio of $0.24 \mathrm{~m}^{-1}$. Hence, the
Table 5 Overview of the sensitivity analysis on thermal and salt recovery efficiency for cycle-4. The associated thermal radii $\left(r_{t h}\right.$, Eq. 5$)$, the solute radii $\left(r_{s}\right.$, Eq. 7), and the ratio between the outside area and the thermal volume of the theoretical cylinder in the aquifer $\left(A_{t o t} / V_{H}\right)$

\begin{tabular}{|c|c|c|c|c|c|c|}
\hline \multirow[t]{2}{*}{ Scenario } & \multirow[t]{2}{*}{$r_{\text {th }}[\mathrm{m}]$} & \multirow[t]{2}{*}{$A_{\text {tot }} / V_{\mathrm{H}}\left[\mathrm{m}^{-1}\right]$} & \multicolumn{2}{|c|}{ Thermal recovery efficiency } & \multirow[t]{2}{*}{$r_{\mathrm{s}}[\mathrm{m}]$} & \multirow{2}{*}{$\begin{array}{l}\text { Salt recovery } \\
\text { efficiency }\end{array}$} \\
\hline & & & $\begin{array}{l}\text { Dens. diff. } \\
\text { compensation }\end{array}$ & $\begin{array}{l}\text { No free } \\
\text { convection }\end{array}$ & & \\
\hline Case 1 & 38.75 & 0.15 & 0.69 & 0.76 & 58.63 & 0.68 \\
\hline $\begin{array}{l}\text { reference } \\
\text { Case } 4\end{array}$ & 56.15 & 0.24 & 0.61 & 0.67 & 84.97 & 0.78 \\
\hline $\begin{array}{l}H_{\mathrm{a}}=10 \mathrm{~m} \\
\text { Case } 5\end{array}$ & 27.40 & 0.17 & 0.65 & 0.73 & 41.46 & 0.59 \\
\hline $\begin{array}{l}V_{\mathrm{i}}=28,350 \mathrm{~m}^{3} \\
\text { Case } 6 \\
V_{\mathrm{i}}=113,400 \mathrm{~m}^{3}\end{array}$ & 54.79 & 0.13 & 0.70 & 0.78 & 82.99 & 0.74 \\
\hline
\end{tabular}


lowest thermal recovery $(0.61)$ was obtained with the density difference compensation method (case 4.b) compared to all other scenarios.

Salt mass recovery efficiency is smallest for the scenarios with the cold saltwater front close to the well screen (e.g. case 5.b; Table 5 and Fig. 7b). Although the injection volume in case 5.b is only half of the reference scenario (case 1.b), saltwater $\left(C_{\mathrm{s}}>12 \mathrm{~kg} / \mathrm{m}^{3}\right)$ is already transported up to a radial distance of $105 \mathrm{~m}$ along the bottom of the aquifer for case 5.b for the first cycle, while this is $124 \mathrm{~m}$ for case 1.b. This means that the relative salt displacement away from the well screen is larger for cases with a cold saltwater front closer to the well screen. For scenarios with a larger radius of injected saltwater $\left(r_{\mathrm{s}}\right)$, the cold saltwater can be transported over a larger distance towards the well screen and hence the relative salt mass loss due to lateral transport away from the well screen is lowered (e.g. cases 4.b and 6.b; Table 5).

\section{Modeling of the pilot study at Auburn University}

The numerical SEAWATv4 modeling results of the two injection-storage-extraction cycles as conducted in the Auburn University field pilot (Molz et al. 1983a) corresponded well with the modeling results by Buscheck et al. (1983). They simulated the two cycles of the field experiment with the computer program PT using a non-linear temperature-density relationship (Bodvarsson 1982).

Figure 9 shows the calculated temperature distributions at the end of the first injection period with an injection temperature of $58.5^{\circ} \mathrm{C}$. The observed preferential flow in the middle high-permeability layer is reproduced. Similar to the modeling results of Buscheck et al. (1983), the higher injection temperature $\left(81^{\circ} \mathrm{C}\right)$ in the second cycle led to stronger free thermal convection resulting in no discernible preferential flow due to the heterogeneous layering (Fig. 10). The thermal recovery

Fig. 9 The color intensity indicates the temperature distribution calculated by SEAWAT at the end of the injection period for cycle-1. Black contour lines indicate the temperature distribution modeled by Buscheck et al. (1983) efficiency calculated for the simulations of the two cycles was 0.58 and 0.41 , respectively, similar to both the experimental results of Molz et al. (1983a) and the numerical calculations by Buscheck et al. (1983), as shown in Table 6. For the second cycle, a smaller transition zone between the hot water volume and ambient groundwater was obtained in this study compared to the results of Buscheck et al. (1983; see Fig. 10). Moreover, enhanced free thermal convection is observed in the SEAWAT modeling results of this study. These differences are likely explained by the smaller grid sizes used in the thermal zone in the SEAWAT model $(\Delta r=0.5 \mathrm{~m})$ than in the model $(\Delta r=4.0 \mathrm{~m})$ of Buscheck et al. (1983), causing less numerical dispersion for heat transport.

\section{Simulating density difference compensation for the Auburn University pilot study}

The potential of the density difference compensation method was tested using the model that adequately modeled the Auburn University field pilot. The required salt concentrations to overcome the buoyancy difference between hot injection water $\left(58.5{ }^{\circ} \mathrm{C}\right.$ for cycle- 1 and $81{ }^{\circ} \mathrm{C}$ for cycle-2) and the ambient groundwater $\left(20^{\circ} \mathrm{C}\right)$ are 19 and $36.6 \mathrm{~kg} / \mathrm{m}^{3}$, respectively (Fig. 2). Free thermal convection was successfully countered for the second cycle (Fig. 11), so that the preferential flow of the hot, saline water in the most permeable layer is more pronounced (compare Fig. 11 with Fig. 10). The preferential flow of saline water into the middle layer of the heterogeneous aquifer results in injected cold saltwater overlying cold fresh ambient groundwater in the bottom layer. The salinity contrast of $36.6 \mathrm{~kg} / \mathrm{m}^{3}$ results in a density difference between ambient fresh water $\left(998.0 \mathrm{~kg} / \mathrm{m}^{3}\right)$ and the cold saltwater front $\left(1,026.1 \mathrm{~kg} / \mathrm{m}^{3}\right)$. Therefore, downward transport

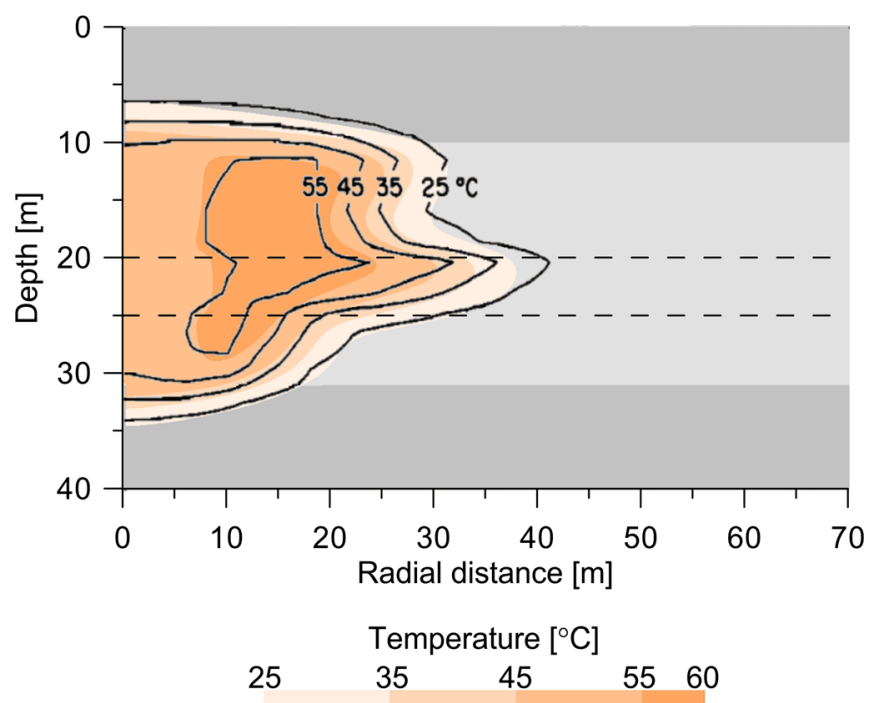


Fig. 10 The color intensity indicates the temperature distribution calculated by SEAWAT at the end of the injection period for cycle-2. Black contour lines indicate the temperature distribution calculated by Buscheck et al. (1983)

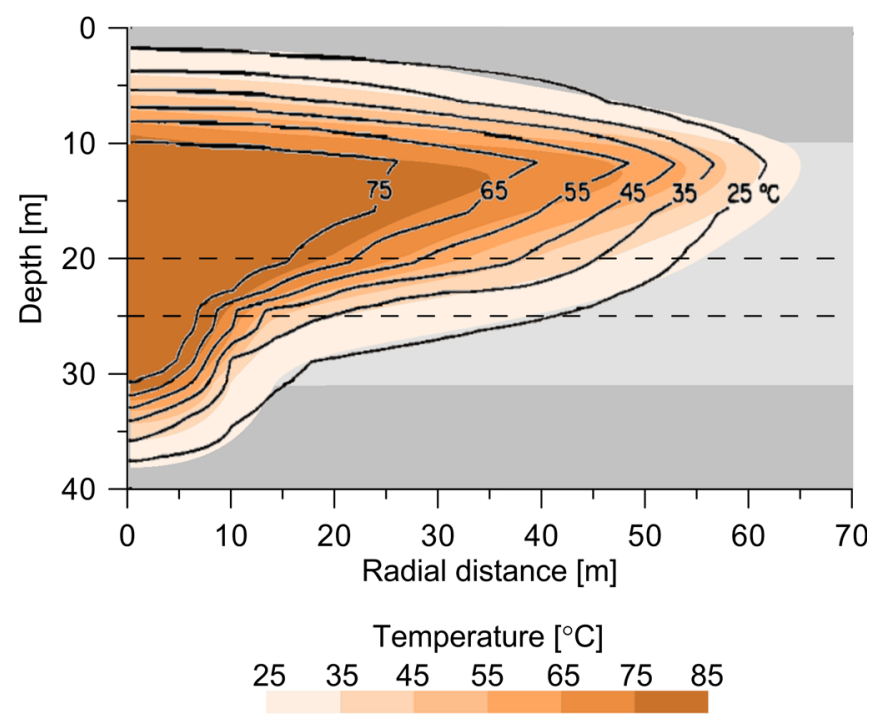

\section{Optimization of thermal recovery efficiency}

The recovery efficiency of regular HT-ATES systems is significantly influenced by both thermal conduction and free thermal convection. The thermal front tilting due to free thermal convection causes unheated ambient groundwater to be recovered at the lower part of the well screen, especially for cases with a small thermal radius $\left(r_{\text {th }}\right.$, case 5.a). Therefore, feasibility of regular HT-ATES is limited (Doughty et al. 1982; Schout et al. 2014). In the past, several suggestions have been put forward to optimize energy recovery during HTATES. In order to reduce the heat loss by free thermal convection during injection and storage, partially penetrating wells can be used to increase energy recovery (Buscheck et al. 1983). However, only a small increase in recovery efficiency was obtained $\left(\Delta \varepsilon_{\mathrm{H}}<0.09\right)$. Most research on optimizing well designs of partially penetrating well systems is done in the field of aquifer storage and recovery (ASR), where density-driven flow occurs due to the salinity contrast between injected freshwater and brackish groundwater (Ward et al. 2007). For these cases, well systems with multiple injection and recovery wells (Miotliński et al. 2014) or multiple partially penetrating wells can be used to successfully increase the recovery of freshwater (e.g. Zuurbier et al. 2014). Also prolonged injection of hot water during the first cycle can be applied to reduce the temperature differences and associated heat loss in subsequent recovery cycles (Sauty et al. 1982).
Table 6 Comparison between experimental and calculated recovery efficiencies

\begin{tabular}{llll}
\hline & $\begin{array}{l}\text { Experimental } \\
\text { (Molz et al. 1983a) }\end{array}$ & $\begin{array}{l}\text { Numerical estimate } \\
\text { (Buscheck et al. 1983) }\end{array}$ & $\begin{array}{l}\text { Numerical estimate } \\
\text { (SEAWATv4, this study) }\end{array}$ \\
\hline Cycle-1 & 0.56 & 0.58 & 0.58 \\
Cycle-2 & $0.40^{\mathrm{a}}$ & 0.40 & 0.41 \\
\hline
\end{tabular}

${ }^{\text {a }}$ Estimated value by Molz et al. 1983a assuming no well screen modification during production 
Fig. 11 The color intensity indicates the temperature distribution calculated by SEAWAT at the end of the injection period for cycle-2 with density difference modification. Black contour lines indicate the temperature distribution calculated by SEAWAT for regular HT-ATES

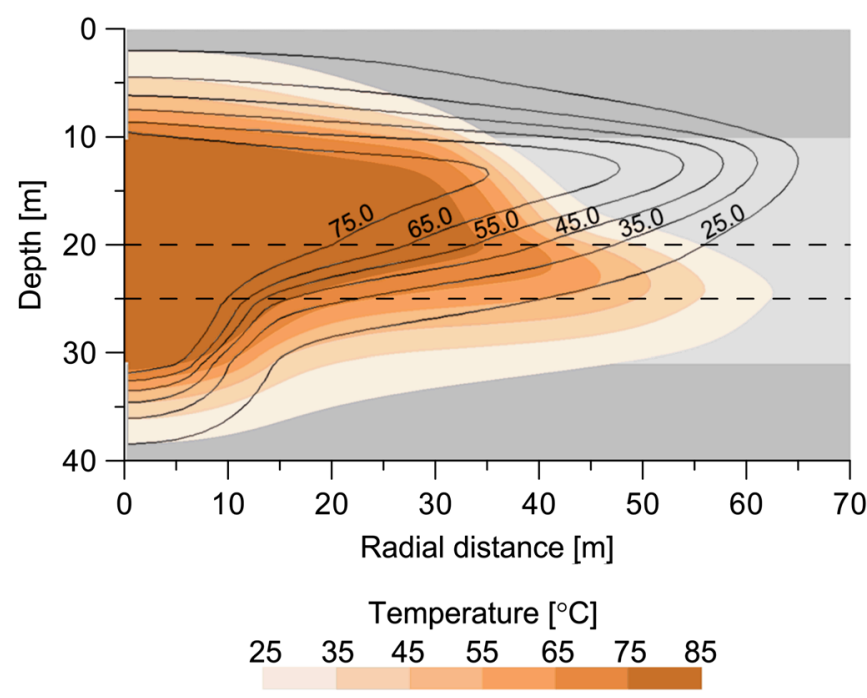

The calculated recovery efficiency for the simulation of seasonal HT-ATES in this study is determined by assuming equal injection and production volumes. In practice, the extraction period may be reduced by maintaining a minimum temperature for extraction. The calculated production temperature over time is significantly higher for HT-ATES with density difference compensation, compared to regular HT-ATES (Figs. 4 and 8). Therefore, the increase in recovery efficiency while using density difference compensation is larger when applying a minimum extraction temperature. For example, the thermal recovery efficiency increase with density difference compensation is relatively small for a low-permeability aquifer (Fig. 7a, case 2.b) while using equal injection and production volumes. However, if a minimum temperature of $60^{\circ} \mathrm{C}$ is used, the extractable volume at a constant extraction rate of $630 \mathrm{~m}^{3} /$ day for regular HT-ATES (case 2.a) was only 17 , $010 \mathrm{~m}^{3}$, whereas this is $30,870 \mathrm{~m}^{3}$ using density difference compensation (case 2.b).

\section{Model validation on the Auburn University field experiments}

Recently, Vandenbohede et al. (2014) validated the approach of Langevin (2008) for heat transport on an ATES test case, where water with a temperature of $17.5^{\circ} \mathrm{C}$ was injected into an aquifer with an ambient groundwater temperature of $10^{\circ} \mathrm{C}$. Due to this small temperature contrast, no density-driven flow was considered for this study. However, the temperature
Table 7 Calculated recovery efficiencies and relative increase with density modification

\begin{tabular}{lllll}
\hline & \multicolumn{2}{l}{ Thermal recovery efficiency } & & $\begin{array}{l}\text { Relative recovery } \\
\text { increase }\end{array}$ \\
\cline { 2 - 3 } & Regular HT-ATES & Dens. diff. compensation & $\begin{array}{l}\text { Salt recovery } \\
\text { efficiency }\end{array}$ \\
\hline Cycle-1 & 0.58 & 0.68 & $17.2 \%$ & 0.69 \\
Cycle-2 & 0.41 & 0.66 & $60.8 \%$ & 0.63 \\
\hline
\end{tabular}


contrasts during HT-ATES are so high that free thermal convection occurs and a density equation of state is required for the simulation. To the best of the authors' knowledge, this is the first study that validates the approach of Langevin (2008) for axi-symmetric density-driven groundwater flow and thermal heat transport at high temperature contrasts $(\Delta T=40$ $\left.60{ }^{\circ} \mathrm{C}\right)$.

For accurate simulation of the thermal convection, a nonlinear density equation of state was implemented in the SEAWATv4 code (Van Lopik et al. 2015). The modeling results accurately reproduce the experimental and numerical data sets of the field experiment at Auburn University (Molz et al. 1983a; Buscheck et al. 1983), while using both an axisymmetric SEAWATv4 model domain and the incorporated non-linear density equation of state (section 'Modeling of the pilot study at Auburn University').

\section{Salinity management of density difference compensated HT-ATES systems}

For this study, a single injection-recovery HT-ATES well through which heat was injected and extracted was considered. Using saline water for heat storage to compensate the density difference with the surrounding cold groundwater results in a significant increase of thermal recovery. From a water resources and economic perspective, rather than adding salt to the water used for HT-ATES, saline water sources could be used, e.g. deeper, more saline groundwater, seawater, or reverse osmosis concentrate (Pérez-Gonzaléz et al. 2012).

In practice, most HT-ATES systems use a doublet well configuration where the hot injection-recovery well, as well as the cold supply well are screened in the same aquifer (e.g. Molz et al. 1983a). For such systems, the use of the density difference method with saline water will result in salt loss due to the salinity contrast between ambient groundwater and injection water for both wells. Alternatively, the use of a monowell configuration (e.g. Zeghici et al. 2015) allows the cold supply well to be screened in a deeper, more saline aquifer which acts as the source for the required salinity.

Depending on the saline water source used for density difference compensation, the chemical composition of the water varies. For regular HT-ATES systems, the risk of mineralprecipitation-induced clogging of wells by, e.g. carbonate and silica minerals is already well known (e.g. Griffioen and Appelo 1993). For most natural saline water sources, however, salinity is mainly defined by sodium and chloride concentrations for which the solubility is controlled by the halite $(\mathrm{NaCl})$ mineral. Since this mineral has temperature dependent solubilities that are well above the salt concentrations required for the HT-ATES relevant temperature range $\left(10-120{ }^{\circ} \mathrm{C}\right.$, Fig. 2), using saline water for density difference compensation is not expected to further increase the risk of mineral precipitation and clogging around the wells.
Besides the risk of temperature dependent mineral precipitation, a high salinity contrast between injection water and ambient groundwater may cause clay particles in the aquifer to swell, or shrink and migrate. Osmotic swelling of clay particles is known to occur when freshwater with a low ion concentration is injected into a brackish or saline aquifer (Brown and Silvey 1977; Molz et al. 1979). The use of saline water for density difference compensation for HT-ATES in brackish or saline aquifers as described in this study, will minimize these effects.

\section{Salinization of the aquifer}

In this study, an ambient salinity of 10,000 ppm was assumed for the simulated cases, since HT-ATES is currently only allowed in brackish or saline aquifers in the Netherlands. This is due to induced (bio)geochemical reactions during hot water storage (Brons et al. 1991; Hartog et al. 2013; Bonte et al. 2013) that could make freshwater unusable for other purposes. The numerical simulations in this study show that the calculated salt mass recovery efficiencies for fully operative seasonal HT-ATES systems range from 0.59 to 0.82 (Fig 7b), resulting in a net salinization of the aquifer. However, the risk of salinization of overlying aquifers appears to be negligible as molecular salt diffusion and saltwater seepage into the upper aquitard was limited in the simulations (Fig. 6d-f). The accumulated salt mass at the bottom of the aquifer after thermal recovery could be recovered by a partially penetrating well screened at the bottom of the aquifer either to minimize the salinization of the aquifer or for re-use in the salinity management of the density difference compensation HT-ATES system.

\section{Summary and conclusions}

Density difference compensation using saline water can be used in HT-ATES systems to overcome the density difference between hot injection water and colder ambient groundwater and prevent free thermal convection of the injected hot water. Additionally, thermal recovery efficiency is significantly increased. For example, calculations for a regular seasonal HTATES at a temperature of $80^{\circ} \mathrm{C}$ in a high-permeability aquifer resulted in a recovery efficiency of 0.40 for the fourth cycle, while density difference compensation gave an efficiency of 0.69 . HT-ATES with density difference compensation can be applied in aquifers with higher hydraulic conductivities and at larger temperatures. This means that a much broader range of aquifers are suitable for HT-ATES and higher capacities can be achieved.

The thermal front moves at a lower velocity than the solute front during hot saline water injection due to thermal retardation. Consequently, downward density-driven flow of the cold 
saltwater in between the two fronts is triggered by the salt concentration contrast between injected cold saltwater and less saline ambient groundwater. Some local displacement of the hot water front towards the well screen is observed, due to the lateral transport of cold saltwater along the bottom of the aquifer.

Saltwater accumulates at the bottom of the aquifer during the extraction period due to continued downward density-driven saltwater flow. Consequently, the total injected salt mass is not fully recovered after extraction. The salt recovery efficiency ranges from 0.59 to 0.82 for the simulated scenarios.

Axi-symmetric density-driven flow simulation in the SEAWATv4 code with an implemented non-linear density equation of state was validated on experimental (Molz et al. 1983a) and numerical results (Buscheck et al. 1983) of a HTATES experiment conducted at Auburn University.

Acknowledgements The authors thank two anonymous reviewers for their constructive feedback, which allowed us to improve the manuscript significantly.

\section{References}

Bodvarsson GS (1982) Mathematical modeling of the behavior of geothermal systems under exploitation. PhD Thesis, University of California at Berkeley; and as Rep. LBL-13937, Lawrence Berkeley Lab, Berkeley, CA

Bonte M, van Breukelen BM, Stuyfzand PJ (2013) Temperature-induced impact on groundwater quality and arsenic mobility in anoxic aquifer sediments used for both drinking water and shallow geothermal energy production. Water Res 47(14):5088-5100. doi:10.1016/j. watres.2013.05.049

Brons HJ, Griffioen J, Appelo CAJ, Zehnder AJB (1991) (Bio)geochemical reactions in aquifer material from a thermal energy storage site. Water Res 25(6):729-736. doi:10.1016/00431354(91)90048-U

Brown DL, Silvey WD (1977) Artificial recharge to a freshwatersensitive brackish-water sand aquifer. US Geol Surv Prof Pap 939

Buscheck TA, Doughty C, Tsang CF (1983) Prediction and analysis of a field experiment on a multilayered aquifer thermal energy storage system with strong buoyancy flow. Water Resour Res 19(5):13071315. doi:10.1029/WR019i005p01307

Doughty C, Hellström G, Tsang CF, Claesson J (1982) A dimensionless parameter approach to the thermal behavior of an aquifer thermal energy storage system. Water Resour Res 18(3):571-587. doi:10. 1029/WR018i003p00571

Griffioen J, Appelo CAJ (1993) Nature and extent of carbonate precipitation during aquifer thermal energy storage. Appl Geochem 8(2): 161-176. doi:10.1016/0883-2927(93)90032-C

Guo W, Langevin CD (2002) User's guide to SEAWAT: a computer program for simulation of three-dimensional variable-density ground-water flow. US Geol Surv Tech Water-Resour Invest 6-A7

Harbaugh AW, Banta ER, Hill MC, McDonald MG (2000) MODFLOW2000, the US Geological Survey modular ground-water models: user guide to modularization concepts and the ground-water flow process. US Geol Surv Open-File Rep 00-92

Hartog N, Drijver B, Dinkla I, Bonte M (2013) Field assessment on the impact of Aquifer Thermal Energy Storage (ATES) systems on chemical and microbial groundwater compositions. European Geothermal Conference, Pisa, Italy, 3-7 June 2013

Hellström G, Tsang CF, Claesson J (1979) Heat storage in aquifers: buoyancy flow and thermal stratification problems. Institute of Technology, Lund, Sweden; and as Rep. LBL-14246, Lawrence Berkeley Lab, Berkeley, CA

Isdale JD, Morris R (1972) Physical properties of sea water solutions: density. Desalination 10(4):329-339. doi:10.1016/S0011-9164(00) 80003-X

Kabus F, Seibt P (2000) Aquifer Thermal Energy Storage for the Berlin Reichstag building: new seat of the German Parliament. Proceedings of the World Geothermal Congress 2000, Kyushu, Tohoku, Japan, May 28-June 102000

Langevin CD (2008) Modeling axisymmetric flow and transport. Ground Water 46(4):579-590. doi:10.1111/j.1745-6584.2008.00445.x

Langevin CD, Thorne DT Jr., Dausman AM, Sukop MC, Guo W (2008) SEAWAT Version 4: a computer program for simulation of multispecies solute and heat transport. US Geological Surv Tech Meth 6A22

Mathey B (1977) Development and resorption of a thermal disturbance in a phreatic aquifer with natural convection. J Hydrol 34(3-4):315333. doi:10.1016/0022-1694(77)90139-1

Meyer CF, Todd DK (1973) Conserving energy with heat storage wells. Environ Sci Technol 7(6):512-516. doi:10.1021/es60078a009

Millero FJ, Poisson A (1981) International one-atmosphere equation of state of seawater. Deep-Sea Res 28A(6):625-629. doi:10.1016/ 0198-0149(81)90122-9

Miotliński K, Dillon PJ (2015) Relative recovery of thermal energy and fresh water in aquifer storage and recovery systems. Ground Water 53(6):877-884. doi:10.1111/gwat.12286

Miotliński K, Dillon PJ, Pavelic P, Barry K, Kremer S (2014) Recovery of injected freshwater from a brackish aquifer with a multiwell system. Ground Water 52(4):495-502. doi:10.1111/gwat.12089

Molz FJ, Melville JG, Parr AD, King DA, Hopf MT (1983a) Aquifer thermal energy storage: a well doublet experiment at increased temperatures. Water Resour Res 19(1):149-160. doi:10.1029/ WR019i001p00149

Molz FJ, Melville JG, Güven O, Parr AD (1983b) Aquifer thermal energy storage: an attempt to counter free thermal convection. Water Resour Res 19(4):922-930. doi:10.1029/WR019i004p00922

Molz FJ, Parr AD, Andersen PF, Lucido VD, Warman JC (1979) Thermal energy storage in a confined aquifer: experimental results. Water Resour Res 15(6):1509-1514. doi:10.1029/WR015i006p01509

Oldenburg CM, Preuss K (1999) Plume separation by transient thermohaline convection in porous media. Geophys Res Lett 26(19):29973000. doi:10.1029/1999GL002360

Olsthoorn TN (1982) The clogging of recharge wells, main subjects. KIWA Communications-72, The Netherlands Testing and Research Institute, Rijswijk, The Netherlands

Palmer CD, Blowes DW, Frind EO, Molson JW (1992) Thermal energy storage in an unconfined aquifer, 1: field injection experiment. Water Resour Res 28(10):2845-2856. doi:10.1029/92WR01471

Pérez-Gonzaléz A, Urtiaga AM, Ibáñez R, Ortiz I (2012) State of the art and review on the treatment technologies of water reverse osmosis concentrates. Water Res 46(2):267-283. doi:10.1016/j.watres.2011. 10.046

Réveillère A, Hamm V, Lesueur H, Cordier E, Goblet P (2013) Geothermal contribution to the energy mix of a heating network when using Aquifer Thermal Energy Storage: modeling and application to the Paris basin. Geothermics 47:69-79. doi:10.1016/j. geothermics.2013.02.005

Sanner B, Karytsas C, Mendrinos D, Ryback L (2003) Current status of ground source heat pumps and underground thermal energy storage in Europe. Geothermics 32(4-6):579-588. doi:10.1016/S03756505(03)00060-9 
Sanner B, Kabus F, Seibt P, Bartels J (2005) Underground thermal energy storage for the German Parliament in Berlin: system concept and operational experiences. Proceedings of the World Geothermal Congress, Antalya, Turkey, 24-29 April 2005

Sauty JP, Gringarten AC, Menjoz A, Landel PA (1982) Sensible energy storage in aquifers, 1: theoretical study. Water Resour Res 18(2): 245-252. doi:10.1029/WR018i002p00245

Schout G, Drijver B, Gutierrez-Neri M, Schotting R (2014) Analysis of recovery efficiency in high-temperature aquifer thermal energy storage: a Rayleigh-based method. Hydrogeol J 22(1):281-291. doi:10. 1007/s10040-013-1050-8

Seibert S, Prommer H, Siade A, Harris B, Trefry M, Martin M (2014) Heat and mass transport during a groundwater replenishment trial in a highly heterogeneous aquifer. Water Resour Res 50(12):94639483. doi:10.1002/2013WR015219

Sharqawy MH, Lienhard VJH, Zubair SM (2010) Thermophysical properties of seawater: a review of existing correlations and data. Desalination Water Treat 16(1-3):354-380. doi:10.5004/dwt.2010. 1079

Vandenbohede A, Louwyck A, Vlamynck N (2014) SEAWAT-based simulation of axisymmetric heat transport. Ground Water 52(6):908 915. doi:10.1111/gwat.12137

Van Lopik JH, Hartog N, Zaadnoordijk WJ, Cirkel DG, Raoof A (2015) Salinization in a stratified aquifer induced by heat transfer from well casings. Adv Water Resour 86A:32-45. doi:10.1016/j.advwatres. 2015.09.025
Voss CI (1984) A finite-element simulation model for saturated-unsaturated, fluid-density-dependent ground-water flow with energy transport or chemically-reactive single-species solute transport. US Geol Surv Water Resour Invest Rep 84-4369

Wallis I, Prommer H, Post V, Vandenbohede A, Simmons CT (2013) Simulating MODFLOW-based reactive transport under radially symmetric flow conditions. Ground Water 51(3):398-413. doi:10. 1111/j.1745-6584.2012.00978.x

Ward JD, Simmons CT, Dillon PJ (2007) A theoretical analysis of mixed convection in aquifer storage and recovery: how important are density effects? J Hydrol 343(3-4):169-186. doi:10.1016/j.jhydrol. 2007.06.011

Zeghici RM, Oude Essink GHP, Hartog N, Sommer W (2015) Integrated assessment of variable density-viscosity flow for a high temperature aquifer thermal energy storage (HT-ATES) system in a deep geothermal reservoir. Geothermics 55:58-68. doi:10.1016/j. geothermics.2014.12.006

Zheng C, Wang PP (1999) MT3DMS: a modular three-dimensional multispecies transport model for simulation of advection, dispersion and chemical reactions of contaminant in ground-water systems: documentation and user's guide. US Army Corps of Engineer Research and Development Center, Contract Report SERDP-99-1, University of Alabama, Vicksburg, MI

Zuurbier KG, Zaadnoordijk WJ, Stuyfzand PJ (2014) How multiple partially penetrating wells improve freshwater recovery of coastal aquifer storage and recovery (ASR) systems: a field and modeling study. J Hydrol 509:430-441. doi:10.1016/j.jhydrol.2013.11.057 